\title{
Ресурсосберегающая технология возделывания раннего картофеля
}

\section{М.Е. Дыйканова, А.Г. Левшин, И.Н. Гаспарян, О.Н. Ивашова}

Представлены материалы исследований влияния технологического приема - проращивания на получение ранней продукции. Прием позволяет сберечь энергетические ресурсы при возделывании раннего картофеля и получить максимальный доход. Отмечается повышение чистого энергетического дохода на 5,9-31,9\%, коэффициентов энергетической себестоимости на 6,332,8\%, а также снижение себестоимости на 0,09-0,33 ГДж/т клубней.

Ключевые слова: световое проращивание, урожайность, себестоимость, рентабельность, чистый энергетический коэффициент, энергетическая себестоимость.

$\mathrm{B}$ последние годы ухудшается экологическая обстановка, все больше используют химические способы поддержания плодородия почвы, увеличиваются мощности с.- х. орудий и движителей, снижается качество продукции и происходит спад экономических показателей [1]. Экономические показатели рассчитывают при постоянно изменяющихся условиях производства [2], происходит инфляция. Использование энергетической оценки наряду с экономической эффективностью позволяет оценить производство более объективно.

В технологию возделывания картофеля раннего мы ввели световое проращивание. Прием требует дополнительных затрат на проращивание. Проращивание ведет к ускорению деятельности ферментов в клубнях и созданию повышенной концентрации растворимых питательных веществ в зоне расположения глазков, что в дальнейшем стимулирует прорастание почек и развитие ростков. Урожай можно получить раньше. Ранняя продукция продается по более высокой цене.

Любое изменение технологии сказывается в дальнейшем на показателях эффективности, введение того или иного приема должно быть оправданным и целесообразным. Целью исследований было энергетическое обоснование технологического приема - светового проращивания в технологии возделывания картофеля раннего.

Исследования проводили в 20172018 годах на участке лаборато- рии овощеводства РГАУ-МСХА имени К.А. Тимирязева. Технология возделывания стандартная. Почва высокоокультуренная, дерново-подзолистая, тяжелосуглинистая. Повторность опытов трехкратная. Степень обеспеченности азотом высокая (12,0 мг/100 г почвы), фосфором - средняя $(8,4$ мг/100 г почвы) и калием - средняя (10,0 мг/100 г почвы). Варианты в опыте были размещены рендомизированным методом. Площадь одной опытной делян-

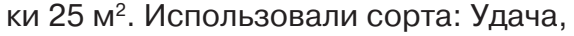
Жуковский ранний, Снегирь, Ред Скарлетт, Метеор. Сроки посадки при прогреве почвы до 6-8 ${ }^{\circ} \mathrm{C}$. При определении энергозатрат пользовались общепринятыми методическими рекомендациями [3, 4, 5].

Таблица 1. Влияние проращивания на урожайность картофеля раннего разных сортов, 2017-2018 годы

\begin{tabular}{|c|c|c|c|c|c|}
\hline Сорт & Вариант & $\begin{array}{c}\text { Урожайность } \\
\text { (15 июля), } \\
\text { т/га }\end{array}$ & Прибавка, \% & $\begin{array}{c}\text { Урожайность } \\
\text { (1 августа), } \\
\text { т/га }\end{array}$ & Прибавка, \% \\
\hline \multirow{2}{*}{ Удача } & контроль & 23,5 & - & 26,1 & - \\
\hline & проращивание & 26,6 & 13,2 & 29,3 & 12,2 \\
\hline \multirow{2}{*}{$\begin{array}{l}\text { Жуковский } \\
\text { ранний }\end{array}$} & контроль & 24,8 & - & 28,8 & - \\
\hline & проращивание & 26,2 & $5,6 \%$ & 29,4 & 2,1 \\
\hline \multirow{2}{*}{ Снегирь } & контроль & 22,3 & - & 24,2 & - \\
\hline & проращивание & 25,1 & 12,5 & 27,9 & 15,2 \\
\hline \multirow{2}{*}{$\begin{array}{l}\text { Ред } \\
\text { Скарлетт }\end{array}$} & контроль & 24,7 & - & 27,8 & - \\
\hline & проращивание & 26,8 & 8,5 & 30,5 & 9,7 \\
\hline \multirow{2}{*}{ Метеор } & контроль & 24,4 & - & 27,4 & - \\
\hline & проращивание & 26,7 & 9,4 & 29,1 & 6,2 \\
\hline
\end{tabular}

Световое проращивание на рассеянном свете привело к образованию верхушечных и боковых глазков. Из них появились короткие толстые ростки темно-зеленой окраски. При ранней посадке пророщенным посадочным материалом растения создали мощную корневую систему, развитую ботву (рис.), раньше образовали клубни, быстрее достигли зрелости, что позволило приступить к уборке в более ранние сроки 15 июля (табл. 1).

При использовании проращивания урожайность выше в зависимости от сорта на 5,6-13,2\% при уборке 15 июля и на 2,1-15,2\% при уборке 30 июля. Хорошо реагирует на проращивание сорта Удача и Снегирь. При уборке в 1 срок (15 июля) прибавка от приема у сорта Удача составила $13,2 \%$ от контроля, у сорта Снегирь $12,5 \%$ от контроля, при уборке во второй срок прибавка чуть меньше у сорта Удача - 12,2\%, а у сорта Снегирь прибавка урожая увеличилась и составила 15,2\% от контроля.

Невысокое увеличение урожайности, вне зависимости от приема, показал сорт Жуковский ранний: при уборке в первый срок увеличение урожайности составило 5,6\%, при уборке во второй срок - 2,1\%. 
Таблица 2. Энергетическая эффективность возделывания картофеля раннего (среднее за 2017-2018 годы)

\begin{tabular}{|c|c|c|c|c|c|c|c|}
\hline Сорт & $\begin{array}{c}\text { Затрачено } \\
\text { энергии } \\
\text { всего, ГДж/га }\end{array}$ & $\begin{array}{l}\text { Урожайность } \\
\text { основной } \\
\text { культуры, т/га }\end{array}$ & $\begin{array}{c}\text { Получено } \\
\text { энергии от } \\
\text { основной } \\
\text { продукции, } \\
\text { ГДж/га }\end{array}$ & $\begin{array}{c}\text { Чистый } \\
\text { энергетический } \\
\text { коэффициент, } \\
\text { ГДж/га }\end{array}$ & $\begin{array}{c}\text { Коэффициент } \\
\text { энергетической } \\
\text { эффективности } \\
\text { посадок }\end{array}$ & $\begin{array}{c}\text { Биоэнергетический } \\
\text { коэффициент } \\
\text { посадок (КПД) }\end{array}$ & $\begin{array}{c}\text { Энергетическая } \\
\text { себестоимость } \\
\text { клубне, ГДж/т }\end{array}$ \\
\hline Удача, БП (контроль) & 67,9 & 26,1 & 122,7 & 54,8 & 0,81 & 1,81 & 2,60 \\
\hline Удача, П & 69,3 & 29,3 & 137,7 & 68,4 & 0,98 & 1,98 & 2,37 \\
\hline $\begin{array}{l}\text { Жуковский ранний, } \\
\text { БП (контроль) }\end{array}$ & 67,9 & 28,8 & 135,4 & 66,1 & 0,96 & 1,96 & 2,40 \\
\hline Жуковский ранний, П & 69,3 & 29,4 & 138,2 & 70,0 & 1,02 & 2,02 & 2,31 \\
\hline $\begin{array}{l}\text { Снегирь, БП } \\
\text { (контроль) }\end{array}$ & 67,9 & 24,2 & 113,7 & 45,8 & 0,67 & 1,67 & 2,81 \\
\hline Снегирь, П & 69,3 & 27,9 & 131,1 & 61,8 & 0,89 & 1,89 & 2,48 \\
\hline $\begin{array}{l}\text { Ред Скарлетт, } \\
\text { БП (контроль) }\end{array}$ & 67,9 & 27,8 & 130,7 & 62,8 & 0,92 & 1,92 & 2,44 \\
\hline Ред Скарлетт, П & 69,3 & 30,5 & 143,4 & 74,1 & 1,06 & 2,06 & 2,27 \\
\hline Метеор, БП (контроль) & 67,9 & 27,4 & 128,8 & 60,9 & 0,89 & 1,89 & 2,48 \\
\hline Метеор, П & 69,3 & 29,1 & 136,8 & 67,5 & 0,97 & 1,97 & 2,38 \\
\hline
\end{tabular}

Это объясняется тем, что растения, полученные из пророщенных клубней, полнее используют питательные вещества материнского клубня, что, в свою очередь, способствует развитию мощной корневой системы. В дальнейшем это влияет и на развитие растения в целом. Более раннее появление всходов способствует использованию зимне-весенних запасов почвенной влаги и растения лучше используют внесенные минеральные удобрения. По данным

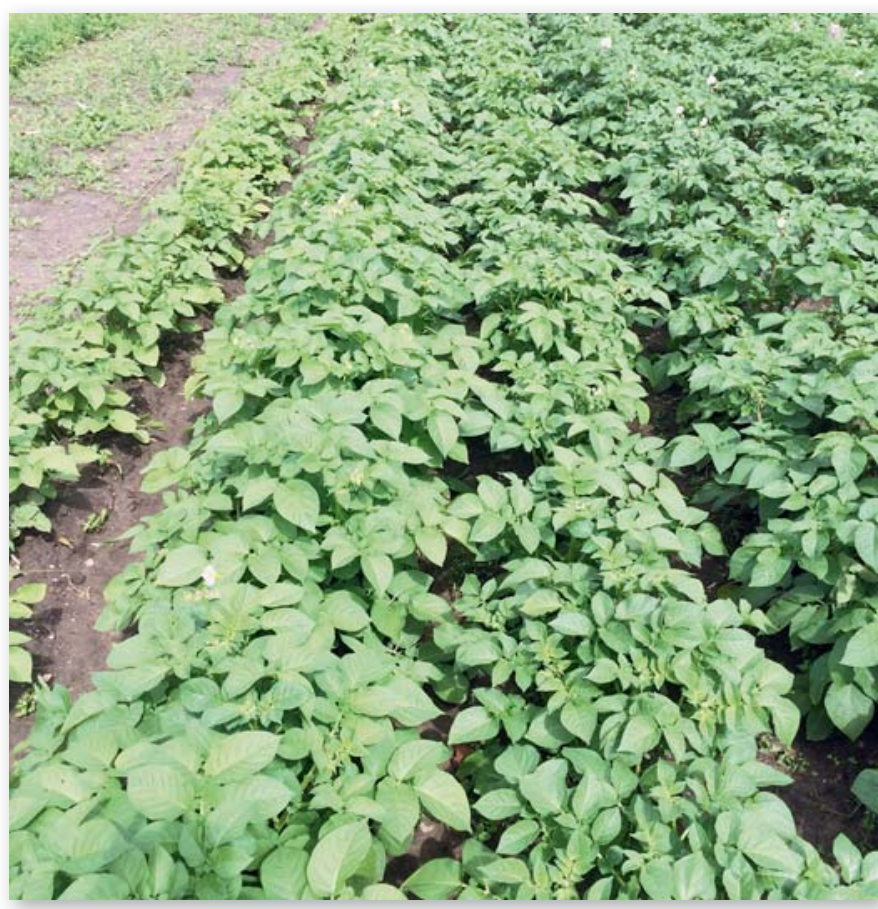

Сорт Удача (начало бутонизации): левый ряд - растения, выращенные из пророщенных клубней, правый - без проращивания
Б.А. Писарева, прибавка урожая может достигать 40-60\%, а в северных районах страны в 2-3 раза выше [6].

Любое увеличение продукции должно сопровождаться снижением себестоимости и повышением рентабельности производства. При дополнительном внедрении технологического приема декапитации повышаются затраты на производство. Выбор того или иного приема и механизированного устройства для его выполнения должен быть обоснован.

Для объективной оценки технологии возделывания раннего картофеля с добавлением декапитации мы определили энергетическую эффективность.

Расчет энергетической эффективности возделывания картофеля проводили у исследуемых сортов при возделывании по отечественной технологии, затраты совокупной энергии (МДж) га) и ее структура при возделывании картофеля (в среднем за 2017-2018 годы) представлены в таблице 2.

Согласно проведенным иссле- дованиям при возделывании картофеля общие затраты энергии составляли (без учета зданий и сооружений) в контрольном варианте 67857,7 МДж/га и в исследуемом варианте 68970,3 МДж/га. В контрольном варианте большая часть энергии приходится на минеральные удобрения $22,82 \%$, машины и с.- х. орудия 20,96\%, посадочный материал $20,78 \%$. Затраты на ГСМ и трудовые ресурсы небольшие, также невысоки затраты на электроэнергию.

В варианте с проращиванием увеличиваются общие затраты, но в структуре затрат идет снижение затрат на удобрение, семена. Ненамного повышаются затраты на машины и с.- х. орудия в связи с дополнительными работами, связанными с проведением светового проращивания, где необходимо вынести посадочный материал из хранилища. Также в этой операции задействованы люди, поэтому идет повышение затрат на трудовые ресурсы, а также увеличивается электроэнергия.

По данным ряда ученых, картофель по совокупным затратам - одна из самых энергоемких культур [5, 7, 8], в наших исследованиях возделывание картофеля тоже требует больших затрат. Согласно проведенным расчетам при возделывании картофеля по отечественной технологии затраты совокупной энергии составляют 67857,7 МДж/га, при добавлении технологического приема возрастает на 1112,63 МДж/га.

Энергия, полученная в урожае, превосходит потраченную на 2,817,4 ГДж/га в зависимости от сорта. 
Наибольшее количество энергии получено при возделывании сорта Ред Скарлетт с использованием проращивания, минимальное количество энергии получено при возделывании сорта Удача в контрольном варианте.

Чистый энергетический коэффициент в зависимости от сорта составлял 54,8-74,1 ГДж/га. При использовании проращивания чистый энергетический коэффициент выше, чем в контроле на 5,9-31,9\%. У сорта Снегирь повышение на 31,9\%, минимальное повышением отмечается у сорта Жуковский ранний.

Энергетический эквивалент продукции, полученный при затрате единицы суммарных энергетический затрат, равен 0,67-1,02 в зависимости от сорта. Максимальные показатели у сорта Жуковский ранний при добавлении проращивания и минимальные показатели у сорта Снегирь в контрольном варианте.

При добавлении светового проращивания в технологию возделывания коэффициент энергетической эффективности повышается на 6,3$32,8 \%$. Также биоэнергетический коэффициент имеет положительное значение и превышает 1.

Наименьшая себестоимость отмечена у сорта Жуковский ранний и составляла 2,40 ГДж/т клубней, максимальная себестоимость у сорта Снегирь - 2,81 ГДж/т клубней. При добавлении технологического приема - проращивания - энергетическая себестоимость снизилась по всем сортам на 0,09-0,33 ГДж/т клубней. Наибольшее снижение энергетической себестоимости при добавлении светового проращивания наблюдалось при возделывании сорта Снегирь, наименьшее у сорта Жуковский ранний.

Таким образом, добавление светового проращивания клубней в технологию возделывания картофеля раннего не требует существенных дополнительных затрат энергии и обеспечивает высокий чистый энергетический доход, высокие показатели коэффициентов, а также низкую энергетическую себестоимость. Такую технологию возделывания можно считать ресурсосберегающей

\section{Библиографический список}

1.Шпилько А.В. и др. Энергетическая эффективность механизации сельскохозяйственного производства. М.: Всероссийский научно-исследовательский институт экономики сельского хозяйства, 2001. 346 с.

2.Анисимов Б.В. и др. Мониторинг современного состояния производства картофеля в России (справоч ник). М.: ФГБНУ ВНИИКХ, 2017. 35 с.

3.Матюк Н.С., Полин В.Д. Ресурсосберегающие тех нологии обработки почвы в адаптивном земледелии: учебное пособие. М.: Издательство РГАУ-МСХА имени К.А. Тимирязева, 2013. 222 с.

4.Сутягин В.П., Туликов А.М., Сутягина Т.И. Системный анализ энергетических потоков в земледелии: учебное пособие для дипломного проектирования. Тверь: «АГРОСФЕРА», 2008. 140 с.

5.Посыпанов Г.С., Долгодворов В.Е. Энергетическая оценка технологии возделывания полевых культур: учебное пособие. М.: Издательство МСХА, 1995. 22 с.

6.Писарев Б.А. Производство раннего картофеля. М. Россельхозиздат, 1986. 287 с

7.Бицоев Б.А. и др. Энергосбережение в технологиях возделывания картофеля раннего // АПК России. 2018. Т. 25. № 24. С. 507-511.

8.Гаспарян И.Н., Дыйканова М.Е. Как повысить урожай раннего картофеля // Картофель и овощи. 2018. № 2. C. $29-31$.

\section{Об авторах}

Дыйканова Марина Евгеньевна, канд. с. - х. наук, старший преподаватель кафедры овощеводства

Левшин Александр Григорьевич, доктор техн. наук, профессор, зав. кафедрой эксплуатации машинно-тракторного парка и высоких технологий в растениеводстве

Гаспарян Ирина Николаевна, доктор с. - х. наук, доцент кафедры эксплуатации машинно-тракторного парка и высоких технологий в растениеводстве. E-mail: irina150170@yandex. ru (ответственный за переписку)

Ивашова Ольга Николаевна, доцент кафедры информационных технологий в АПК

ФГБОУ ВО РГАУ-МСХА ИмеНИ К.А.

Тимирязева

Resource-saving technology of cultivation of early potatoes

M.E. Dyikanova, $P h D$, senior lecturer, department of vegetable growing A.G. Levshin, $D S c$, prof., head of

department of management of machinery and tractor fleet and high technologies in crop production

I.N. Gasparyan, DSc, associate professor of department of management of machinery and tractor fleet and high technologies in crop production. E-mail: irina150170@ yandex.ru (responsible for correspondence) O.N. Ivashova, associate professor of department of information technologies in agriculture

Summary. The article presents the research materials of the influence of technological reception - germination on the production of early products, allowing saving energy resources in the cultivation of early potatoes and getting the maximum income. There is an increase in net energy income by 5.9$31.9 \%$, coefficients of energy cost by 6.3$32.8 \%$, as well as cost reduction by 0.09 $0.33 \mathrm{GJ} / \mathrm{t}$ of tubers.

Keywords: light germination, yield, cost, profitability, net energy ratio, energy cost.

\section{Ксения Леонидовна Алексеева}

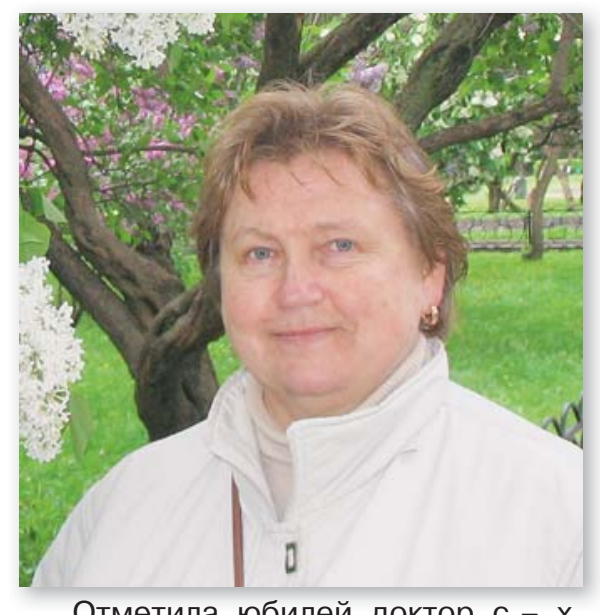

Отметила юбилей доктор с.- х. наук, зав. лабораторией биологических методов защиты растений и грибов ВНИИО - филиала ФГБНУ ФНЦО, заслуженный деятель науки Московской области Ксения Леонидовна Алексеева.

К.Л. Алексеева родилась в г. Ленинграде, с отличием окончила биолого-почвенный факультет Ленинградского государственного университета, работала инженеромтехнологом в ЦКТБ «Промтеплица», старшим агрономом по защите в совхозе «Заречье». Более 35 лет она работает в отделе защищенного грунта ВНИИО, из них 20 лет возглавляет направление защиты растений. Результаты проведенных ею многолетних производственных испытаний средств защиты легли в основу организации системы защитных мероприятий от болезней и вредителей в тепличных и грибоводческих хозяйствах России.

Она - автор более 180 научных работ, включая 5 монографий и 12 патентов на изобретения. Под ее руководством защищены 5 кандидатских диссертаций. Более 10 лет читала курс лекций по грибоводству на кафедре овощеводства РГАУ-МСХА имени К.А.Тимирязева. Юбиляр поддерживает творческие связи с научными и производственными организациями России, стран ближнего и дальнего зарубежья.

Ученые-овощеводы и грибоводы России, коллектив ВНИИО - филиала ФГБНУ ФНЦО, редакция журнала «Картофель и овощи», ученики и коллеги от всей души поздравляют Ксению Леонидовну, желают ей крепкого здоровья, счастья, благополучия и новых успехов во всех ее творческих начинаниях. 